\title{
Do trabalho coletivo na escola: encontros na diferença
}

Resumo: O presente artigo trata da constituição de um grupo de formação composto por professoras das primeiras séries do Ensino Fundamental de uma escola municipal no interior do Estado de São Paulo. O grupo redefiniu a prática do reforço instituída na escola e assumiu a corresponsabilidade pela aprendizagem dos alunos dessas séries que precisavam de outros tempos para aprender. Esse fato potencializou o empenho conjunto das professoras ao promover um trabalho coletivo para acolher todas as crianças. A dimensão coletiva apareceu quando o grupo, perante os conflitos vividos a partir da prática escolar, tomou consciência deles e definiu objetivos e ações que possibilitaram aos seus alunos aprender. Explicita-se que desenvolver um trabalho coletivo não implica o apagamento das diferenças e considera-se que, com elas, é possível haver coincidência dos objetivos pelos quais os participantes de um grupo trabalham.

Palavras-chave: formação de professores; trabalho coletivo; escola.

\section{About collective work at school: encounters in the difference}

Abstract: This article deals with the establishment of an educational group of teachers who work with early grades of primary education in a municipal school in the state of São Paulo. The group redefined the established practice of make-up classes established in the school and assumed the co-responsibility for the learning of those children who needed extra time for learning. This fact encouraged teachers to work together to promote a collective effort to help all children. The collective dimension appeared when teachers, aware of the conflicts experienced in school practice, defined objectives and actions that enabled students' learning. We explicit that the development of collective work does not imply the absence of differences and consider that it is possible to agree on the objectives that the group's participants work for, in spite of the differences.

Key words: teacher education; collective work; school.

Introdução

O discurso das políticas educativas e a literatura educacional enfatizam a importância da gestão democrática da escola e do trabalho coletivo dos professores. A consideração desses aspectos pode levar à melhoria da qualidade de ensino, pois são concebidos como mecanismos que possibilitam alterar práti-

* Professora do Departamento de Educação e do Programa de Pós-Graduação em Educação do Instituto de Biociências da Unesp (Campus Rio Claro), Rio Claro, SP, Brasil. Ichaluh@rc.unesp.br 
cas pedagógicas (Spósito, 2001). Proponho discutir essa problemática, considerando os conceitos de coletividade, trabalho coletivo e dimensöes do trabalho coletivo, a partir de minha experiência com um grupo de professoras no interior de uma escola de Ensino Fundamental da Rede Municipal de Ensino de Campinas-SP.

A Secretaria Municipal de Educação $(\mathrm{SME})^{1}$ desse município, no último ano de sua gestão, possibilitou a constituição de um Grupo de Trabalho em cada uma das escolas dessa rede, com o intuito de que os professores refletissem sobre a especificidade da alfabetização. Foi ampliado o horário de trabalho dos professores dentro da escola para favorecer a reflexão conjunta sobre essa temática. A proposta foi realizada com os professores das 1as., 2as. e 5as. séries das escolas de Ensino Fundamental, já que, nessas séries, evidenciavam-se dificuldades em relação à aquisição de leitura e escrita.

Estive inserida como pesquisadora em uma escola de Ensino Fundamental da referida rede para acompanhar e participar dos espaçostempos de reflexão, instituídos na tentativa de compreender como as professoras, em forma conjunta, recriavam a política pública de formação e assumiam a sua própria formação. Neste texto narro a constituição e o desenvolvimento do grupo que foi instituído na referida escola e denominado "Grupo de Reflexão sobre Letramento e Alfabetização" (GA). Esse grupo teve como objetivo refletir sobre os processos de aquisição da leitura e da escrita, tomar consciência da própria prática e redefinir o trabalho com as classes de alfabetização. A partir dessa experiência problematizo, a seguir, as possibilidades de desenvolver um trabalho coletivo por um grupo de professoras no âmbito da escola, apontando as motivaçōes que levaram as participantes a gerar uma ação conjunta a favor dos alunos. Ao analisar tal ação, procuro compreender as dimensões do trabalho coletivo desenvolvido por esse grupo.

\section{A constituição do grupo de formação}

Do GA participavam as professoras das 1as. e 2as. séries, a orientadora pedagógica, a diretora e eu, a pesquisadora. O grupo iniciou os encontros em março de 2004 e continuou até dezembro de 2005. Os encontros eram semanais e, nesse espaço, a responsabilidade pela coordenação do encontro era assumida por todas as participantes.

Uma das primeiras açōes desenvolvidas pelo grupo foi a socialização, por parte da professora Ítala ${ }^{2}$ de um curso de alfabetização oferecido pela SME do

I. Faço referência à gestão da Secretaria de Educação de Campinas no período 200 I -2004.

2. Meu agradecimento às professoras citadas, que me autorizaram a socializar suas falas. 
qual ela havia participado. Outras ações desenvolvidas nesses dois anos foram: apresentação da dissertação de mestrado de uma das professoras, focalizando como tema a ansiedade nas crianças; apresentação da dissertação de mestrado da diretora da escola sobre leitura e escrita; oficinas de matemática coordenadas pela pesquisadora; definição dos objetivos de português para as 1as e 2as séries (instaurando o pré-conselho); análise de produçōes dos alunos; leituras de textos, vídeos que tratavam sobre alfabetização; seleção e compra de material didático; análise de atividades desenvolvidas pelas professoras com os alunos nas suas salas de aula, entre outras.

Nos primeiros encontros, percebeu-se que as discussóes sobre letramento e alfabetização estavam permeadas por uma questão que começou a ecoar no grupo: o interesse das professoras por saber como fazer as intervenções adequadas no processo de aprendizagem dos alunos:

FT1 ${ }^{3}$ - Fita GA, 28 de abril de 2004

Ítala: No curso de alfabetização foram colocadas algumas questōes pela professora de 2a. série justamente disso. De ter o grupo fragmentado [faz referência à heterogeneidade], inclusive uma tarefa de casa que a gente vai ter que fazer dentro da sala, é de você estar fragmentando, dividindo a sala em grupos de acordo com as fases da escrita, em seu caso [Mônica] vocêsó tem um grupo que não está alfabetizado, não é?

Mônica: Dois tipos.

Ítala: Para esse grupo de alfabéticos ${ }^{4}$, vocêpode, por exemplo, ainda ela comentou com a gente, dar uma música, que eu vou ter que fazer, a escuta dirigida de uma música conhecida, mas que eu nunca trabalhei a letra. Os alfabéticos, a gente exige a ortografia correta, então eles vão ter que se empenhar em aquela ortografia correta.

Mônica: Correto, esseéo trabalho que eu quero fazer e não consigo comeles.

Ítala: Eles estão lá e eles dão conta do trabalho deles e você fica com aquele grupo que você está buscando alfabetização. [...]

Ítala: Com a mesma música. Para aquela turma você vai cobrar ortografia correta a mísica inteira. Para este grupo, se você conse-

3. FT — Código retativo às fitas gravadas em áudio dos encontros do Grupo de Reflexão sobre Letramento e Alfabatização.

4. Smolka (2003) aponta que as pesquisas desenvolvidas por Ferreiro e Teberosky explicitam as funções e a funcionalidade da escrita no processo de alfabetização numa situação experimental, procurando estabelecer padrões evolutivos como sequência de níveis, apresentando um modo de organização dos conhecimentos infantis em termos de hipótese pré-silábica, silábica, silábicoalfabética, inferidas pelas respostas das crianças. A crítica da autora é que analisam a relação da criança com a escrita, como objeto de conhecimento, independente das condições de interação social e das situações de ensino. 
guir uma frase, que eles escrevam silabicamente a frase, mas que eles argumentem, que eles discutam, que eles cheguem a um lugar, a um caminho por conta deles. Isso já é uma intervenção que faz crescer $[\ldots]$

As questóes que mais preocupavam as professoras eram que tipo de intervençóes teriam que realizar com os seus alunos para favorecer a aprendizagem deles; e essas intervençôes dependiam do nível (pré-silábico, silábico, silábicoalfabético) no qual eles estivessem. A professora Ítala enfatizava mais uma vez a necessidade de saber como intervir:

FT1 - Fita GA, 28 de abril de 2004.

Ítala: O que eu gostei aqui [o curso] é que justamente vêm as intervençôes que a gente precisa, que às vezes a nossa prática, a gente sabe, mas na hora de registrar, são os objetivos, os desafios que você vai colocar para cada grupo, o que você precisa, o procedimento. [...] porque o nosso grande problema éa intervenção, não é?

Intervir, nesse contexto, implicava pensar na heterogeneidade presente na sala de aula e fazer todos avançarem, cada um em função de sua singularidade. Lidar com a heterogeneidade é uma das instâncias mais complexas no trabalho diário da sala de aula, não só porque são muitos alunos na sala, mas também porque, como pano de fundo, aparecia, a partir das falas das professoras, a falta de um conhecimento que lhes desse elementos para saber como fazer com cada aluno e em cada situação. Que conhecimentos seriam esses? De que conhecimentos as professoras sentiam falta? Remeto-me a Zeichner (2002), que aponta que os professores precisam saber como explicar os conceitos complexos, como conduzir discussōes, como avaliar a aprendizagem, como desenvolver a aula, quais as estratégias, etc. Também afirma que essa reflexão está atrelada à luta pela justiça social. Segundo Zeichner (2002), é preciso assegurar que os professores possuam os conteúdos e a fundamentação pedagógica necessários para ensinar, mas também é preciso assegurar que os professores tomem decisões em seu trabalho com uma consciência maior sobre as consequências potenciais das diferentes escolhas que fazem.

Continuando com o percurso do grupo, tivemos também a oportunidade de assistir a uma série de vídeos, a partir dos quais também foram aparecendo outras questóes relacionadas à escrita e à intervenção. Tanto os textos como os vídeos mostraram-se como estratégias importantes que mediaram a relação entre a prática e a teoria, possibilitando o conhecimento de outras formas de promover a alfabetização. Resgato aqui as consideraçōes da professora Andréa que, a partir de um dos vídeos assistidos, problematizou uma das situaçóes de apredizagem nele mostrada; e seus comentários explicitavam a grande preocu- 
pação das professoras que participaram do GA: como dar conta de alguns alunos que precisavam de mais tempo para aprender?

FT2 - Fita GA, 05 de maio de 2004.

Andréa: O adulto também passa pelos mesmos niveis de escrita que a criança passa. Passa pelas mesmas etapas e ai [vídeo] mostra uma sala de alfabetizaçãa, e uma palavra que o rapaz está tratando de escrever e a professora falou que era arroz. Então era assim: ARROIZI. E ai ele ficava tentando escrever, ele usava todas as letras de arroz, só que a ordem ele trocava tudo, ele colocou no meio [...] Então acho que foi assim, foram umas 8 tentativas. Ela [professora] intervindo, ela escrevendo, ela fazendo ele ler, ali ele ia mudando [...]

Mas a gente vê, assim, que éum trabalho individual esse da intervenção, e que você realmente precisa sentar aí do lado das pessoase ficar, ter essa disponibilidade de ficar intervindo ali, mais um pouco. Eaiéassim, você quer mudar alguma coisa, para conseguir realmente [...], é uma coisa que eu sinto assim, que a gente não tem todo esse tempo com as nossas crianças, que säo 30 que a gente tem, e ai vocêpega 2 minutinhos cada um, 5 minutos com aquele que precisa mais, vai indo, vai indo, vai indo. [...]

A preocupação era: como intervir? Quais as estratégias de intervenção? E, além disso, como fazer no espaçotempo da sala de aula para dar conta de cada um dos alunos? A heterogeneidade estava presente, ela aparecia.

No primeiro ano do grupo, percebi a preocupação e o esforço das professoras para que os seus alunos escrevessem. Eu percebia que o foco estava na aprendizagem da escrita e não se problematizavam questôes acerca de outros conhecimentos. Eu me perguntava o porquê de tanta inquietação em alfabetizar, letrar! As professoras estavam preocupadas em ter que dar conta da escrita de seus alunos. A seguir, um fragmento de um dos encontros no GA que deixam em evidência essa cobrança.

FT2 - Fita GA, 5 de maio de 2004.

Ítala: Mas Andréa e eu, também a gente tem essa prática de préescola; o outro dia, a gente estava comentando no nosso periodo de entrosamento, de integração (rs), e o que bate na nossa vivência é a cobrança, é a cobrança; [...]

Laura: Qual éessa cobrança?

Ítala: A aprovação, no final do ano [...]. Se é um processo contínuo, um aluno silábico-alfabético ele poderia vir para uma $2 a$. série, só que ai eu mando um aluno silábico-alfabético para a 2 a.série e o professor da $2 a$. série não aceita porque ele ainda é silábico-alfabético, ele não está alfabetizado, ou seja, na 1a. série ele deveria sair alfabetizado! E o silábico-alfabético em um instantinho [...] 
Acredito que a questão da cobrança tenha estreita relação com a avaliação dos alunos, já que, dentro das ações desenvolvidas em 2004, mereceu uma importante atenção a instauração do Pré-Conselho dentro do espaço do GA. Isso significava que, antes da realização do Conselho ${ }^{5}$ de classe/série com a participação de todos os profissionais responsáveis pelos alunos e alunas das 1as. às 4as. séries, realizar-se-ia, no espaçotempo de GA, a discussão e a análise das produçóes escritas dos alunos das 1as. e 2as. séries.

Desse modo, o fantasma do Conselho seria amenizado dentro do GA, já que as professoras levariam para esse grupo as produçóes escritas de alguns dos seus alunos para que todas elas avaliassem a aquisição da escrita deles. Na época em que se instaurou o Pré-Conselho, Mabel, a diretora da escola, iniciou a sua participação no grupo. O Pré-Conselho trouxe para a discussão do grupo uma questão que inquietava todas, uma contradição, um conflito criado pela escola seriada: a avaliação. E, para problematizar essa questão, a seguir trato de um acontecimento que refletiu o poder que tem o processo de avaliação dos alunos na escola.

\section{A contradição e os conflitos vividos}

Aponto que a questão da contradição apresentou-se intimamente ligada ao processo de avaliação na escola. As professoras explicitavam o seguinte conflito: se iriam considerar o avanço das crianças em relação ao processo de aprendizagem de cada uma delas ou se teriam que colocar uma nota em função de um produto definido segundo outros parâmetros. Diante dessa contradição, Mabel fez considerações em relação à esquizofrenia da escola. Esquizofrenia porque dois movimentos contraditórios apresentam-se no momento de avaliar: o processo de ensino e o processo de construção de conhecimento. A seguir, apresento algumas falas da diretora em relação aos dois processos contraditórios que ganham vida nas escolas:

FT4 - Fita GA, 25 de maio de 2004.

Mabel: Eu acho que a escola tem dois processos que caminham atualmente, que é uma filosofia, essa da seriação e a outra que é da

5. Para ampliar a discussão sobre Conselho de Classe, ver Dalben (2004). O Conselho de Classe é um órgão colegiado, presente na organização da escola, no qual os professores, junto com os coordenadores pedagógicos, ou supervisores e orientadores educacionais, reúnem-se para refletir e avaliar o desempenho pedagógico dos alunos das diferentes turmas, séries, ou ciclos. Segundo a autora, o Conselho apresenta algumas características que o diferenciam de outros órgãos colegiados, e são essas características que lhe outorgam importância para o desenvolvimento do projeto pedagógico da escola: a participação direta dos profissionais que atuam no processo pedagógico; sua organização interdisciplinar; a centralidade da avaliação escolar como foco de trabalho da instância (destaques meus). 
produção de conhecimento. Então são dois processos diferentes. Isso é como se fosse um processo esquizofrênico do ponto de vista do quê? Do professor, que tem que dar conta disso, por exemplo, na avaliação. Por isso é que o Conselho e a avaliação são muito dolorosos, porque, na verdade, vocêtem que dar conta de dois processos que são contraditórios, contraditórios na raiz, e um é o seguinte, é a seriação que supõe, que term uma linha. O que a seriação supõe? Que o aluno vai sair daqui na 1a. série, ele vai caminhar por esta linha e ele vai chegar aqui, este é o critério mínimo. [...] E aí vocêpassa à outra série se você atinge esse critério mínimo, essa que é a ideia da seriação. Tudo, a seriação está dividida, quer dizer, ela divide os conteúdo e ela está baseada em conceitos básicos e conceitos complexos e para você adquirir um conceito complexo, você tem que adquirir vários básicos para adquirir o complexo. Por exemplo, a soma vem antes da multiplicação, vem antes da subtração [...] Então você vai ensinar, então se você vai ensinar letras, você vai ensinar as letras mais fáceis, [...] A letra mais fácil é definida a partir da autoridade da lingua, ou seja, ou éo professor, ou é a escola, ou é a universidade, ou são os estudiosos, são os cientistas, são os pesquisadores, essas pessoas que vão definir qual éo mais fácil para o mais difícil. Não parte do ponto de vista do falante, ou do aprendiz, aquele que vai aprender. O outro processo, que éo processo de construção do conhecimento, que é o construtivismo, o interacionismo, parte da ideia de que as crianças estão em pontos diferentes, não existe uma linha de aprendizagem, existem muitas linhas de aprendizagem [...] Para que o aluno aprenda, ele tem que ter alguma coisa anterior, que seria você entender como conhecimentos básicos.

Essas palavras ajudam-nos a compreender o caminho tortuoso da escola seriada que tem, no fim do percurso, um determinado aluno. Mas também nos permitem enxergar que, além desse caminho, existe um outro, que não se cruza com este e que tem a ver com o processo de construção de conhecimento por parte dos alunos. Dois processos que não se cruzam e que olham os alunos com diferentes olhos. Essa é a contradição vivida pelas professoras, fundamentalmente, no momento de avaliar. A preocupação surge quando, no momento da avaliação, aparecem aqueles alunos que não conseguem aprender nos tempos que a escola estipula. Quais as brechas que existem na escola para fazer com que todos os alunos aprendam?

Vários autores têm tratado das dificuldades que há na escola para dar conta da aprendizagem de todos os alunos. Segundo Gimeno Sacristán (1997), a escola foi configurada, tanto na sua ideologia como nos seus modos organizativos e pedagógicos, como um instrumento de homogeneização e de assimilação dentro da cultura dominante e, como tal, não consegue acolher e dar expressão às singularidades. Os alunos não conseguem adaptar-se aos modos com que o 
conhecimento é oferecido nem às condutas que deles se esperam. $\mathrm{O}$ autor aponta que são múltiplos os fatores que contribuem para a taylorização e homogeneização dos tratamentos pedagógicos: a estrutura organizacional do sistema educativo e das instituiçōes que graduam as aprendizagens a serem transmitidas; a ordenação do currículo, adotando tempos próprios para cada tipo de conteúdo; o controle interno/externo dos conteúdos, fazendo com que os professores imponham uma cultura de certa forma homogeneizada e tipos/níveis de rendimentos padronizados; escassa variedade de espaços, estímulos e recursos culturais para a aprendizagem, usando fontes uniformizadas de informação.

Na mesma linha, Cortesão (1999) lembra que, após ter sido justificado que o insucesso de alunos e alunas tinha a ver com o ambiente sociocultural "desfavorecido" no qual estavam inseridos, passou-se a pensar na responsabilidade que a própria escola tinha perante aqueles processos. Segundo a autora, a escola oferece, geralmente, um tipo único de processo de ensino, ainda quando a população escolar é heterogênea na origem social, geográfica, étnica, etc. Como aponta Cortesão (1999), "a escola, a educação, constrói-se e funciona habitualmente para o 'aluno-tipo' para o 'cliente-ideal' pelo que a presença, a participação de grupos com comportamentos diferentes é por vezes muito perturbadora do seu funcionamento" (p. 4).

Ao pensar na escola que temos na sociedade capitalista, seriada e homogeneizadora, Freitas (2003) faz referência a ela como a "forma escola" e pergunta-se se ela está, de fato, voltada a ensinar tudo a todos, como apontava Comenius. Segundo o mesmo autor, os alunos apresentam diferentes ritmos de aprendizagem, mas, na escola, há um único tempo de aprendizagem, há um mesmo tempo para todos, o que traz como consequência o fato de que alguns dominem tudo e outros menos. Segundo Freitas (2003), para unificar os desempenhos, temos que diversificar o tempo de aprendizagem, sendo preciso que cada aluno avance a seu ritmo, usando todo o tempo que lhe seja necessário. $\mathrm{O}$ autor enfatiza, ainda, que não é suficiente que o aluno tenha todo o tempo necessário, mas que tenha ajuda diferenciada para aprender quer por materiais diversificados quer pelo apoio de que precisa no processo de aprendizagem; ou seja, importa disponibilizar apropriadas formas de ajuda no trato com os diferentes alunos.

E, pensando na concepção do tempo escolar, trago as considerações de Pérez de Lara (2006), que nos fazem refletir acerca desse tempo. A autora trata do tempo escolar e sua relação com os alunos que são imigrantes e aponta que parece que eles "llegan tarde ${ }^{6}$ a nuestras clases". Pensando na heterogeneidade da população que está presente na escola, poderíamos pensar que não só os

6. Pérez de Lara aponta que a ideia de "llegar tarde" [chegar tarde] foi sugerida por Skliar (Skliar apud Pérez de Lara, 2006). 
alunos imigrantes poderiam "llegar tarde", mas também que há outros alunos que não conseguem chegar no tempo que a escola define. E, se insisto na questão de considerar o "outro tempo" que alguns alunos precisam na escola, é porque justamente é esta a questão que tocava às professoras: como fazer para, de fato, acolher todas as crianças na escola, para que todas tivessem a possibilidade de aprender.

Como as professoras lidariam com as questōes até aqui levantadas: a esquizofrenia da escola, a avaliação na escola e os tempos de aprendizagem dos seus alunos. Explicitados alguns dos conflitos vividos pelas integrantes do GA e considerando a experiência com elas, proponho-me a fazer um diálogo com alguns teóricos para ampliar a compreensão tanto dos acontecimentos vividos nesse grupo como das açōes que, posteriormente, foram desenvolvidas por ele para tentar resolver os conflitos.

A partir da leitura de Bakhtin (1999), percebo como é que os membros de uma coletividade podem ter maior ou menor consciência (atividade mental) da noção de "classe para si". Bakhtin exemplifica essa questão, trazendo como exemplo as diferentes formas de como pode ser experimentada a fome pelos membros de uma coletividade. A vivência da fome, segundo ele, vai depender fundamentalmente das características assumidas pelos membros de tais coletividades. Segundo Bakhtin, quando os membros de uma coletividade estão unidos por "vínculos materiais objetivos", por exemplo, quando uma classe social já amadureceu a noção de "classe para si" (batalhão de soldados, operários reunidos no interior da usina, trabalhadores numa grande propriedade agrícola do tipo capitalista), os membros dessas coletividades têm a possibilidade de desenvolver, a partir de sua atividade mental (consciência), "o protesto", sem deixar lugar para uma "mentalidade resignada e submissa". Assim, Bakhtin (1999) diz que "é aí que se encontra o terreno mais favorável para um desenvolvimento nítido e ideologicamente bem formado da atividade mental" (p. 116). O autor deixa em evidência a importância de "conscientizarmo-nos" acerca dos conflitos vividos. Mas o que seriam os "vínculos materiais objetivos" considerados dentro do GA que, como já referido, tinha como um dos seus objetivos "tomar consciência" de sua própria prática? Para refletir sobre essas questôes, dialogo com alguns autores que apontam a importância de constituir uma coletividade de professores no âmbito da escola, já que isso tem como consequência assumir a gestão da escola.

Segundo Davini (2001), os programas de formação e as políticas de formação continuada deveriam priorizar os processos comunicativos, os trabalhos coletivos, a revalorização dos espaços comuns de aprendizagem e a construção do conhecimento compartilhado. Segundo a mesma autora, o problema das escolas e da docência não é um problema "privado". Considera que os professo- 
res, perante as dificuldades encontradas nas escolas, assumem-nas e responsabilizam-se por elas por entre as paredes da sala de aula, considerando assim que as dificuldades são próprias, individuais e pessoais. Segundo a autora, porém, não é potencialmente transformador continuar utilizando esse mecanismo de caráter "privado" em um tema que é "público". Ainda considerando a relação público-privado, Gauthier (1998) aponta que o professor faz julgamentos constantemente, mas que eles, e as razões que os fundamentam, nunca são conhecidos. O autor considera que o professor julga em particular, no segredo da sala de aula, sua jurisprudência é secreta, privada. Por esse motivo, o autor explicita a necessidade de tornar públicas as experiências dos professores.

Para Zeichner (2002), que os professores vejam os problemas como próprios é uma consequência do isolamento entre eles e da desconsideração ao contexto social do ensino, o que não permite que eles olhem para o impacto que a estrutura das escolas e dos sistemas escolares tem para a prática educativa. Kramer (2003) também destaca a importância da dimensão coletiva no trabalho das professoras, ao considerar a necessidade de possibilitar um espaço de linguagem para que elas possam expor sua prática e, nessa interlocução, enxergar que os problemas são comuns e não individuais.

Muitas vezes, no GA, as professoras diziam que o que as unia eram os problemas, que, como já apontado, tinham a ver com a esquizofrenia da escola, com o momento da avaliação e com saber lidar com o tempo individual dos alunos. Conflitos que as professoras, nessa coletividade, tiveram que enfrentar. Importa destacar, neste trabalho, quais as estratégias que o GA encontrou para fazer frente a esses conflitos. A criação, a constituição e o desenvolvimento do Grupo de Apoio (GAP) foram uma saída, uma brecha possível que o GA desenvolveu na escola.

\section{A implementação de uma prática coletiva}

A partir do ano de 2005, o GA implementou uma mudança em relação ao Trabaho Docente Individual (TDI). O TDI era um espaço já instituído nas escolas dessa rede, destinado ao atendimento de dúvidas de alunos, aulas de reforço e de recuperação paralela, atendimento a pais de alunos e outras atividades definidas com a equipe escolar. Isso implicava que aqueles alunos que, segundo as professoras, precisavam de outros tempos para aprender, além do da sala de aula, tinham a possibilidade de estar com a sua professora fora do horário escolar para ter outras experiências de aprendizagem. Na escola, o TDI acontecia dessa forma: cada professora assumia a responsabilidade pela aprendizagem dos seus próprios alunos no horário após a aula, para oferecer o reforço.

Mas, nas primeiras reuniōes do GA do ano de 2005, as professoras das 1 as. séries socializaram uma experiência vivida por elas no final do ano de 2004, 
quando tiveram que compartilhar a mesma sala no momento de dar reforço para os seus alunos. Essa experiência fez com que as duas professoras refletissem sobre a possibilidade de efetivar alguma mudança em relação a como vinha sendo desenvolvido o TDI na escola. A partir dessa experiência, promoveu-se uma discussão no GA e pensou-se em alternativas para o espaço de TDI. Assim, foi ressignificada a prática do reforço para os alunos dessas séries: deixou de ser uma prática solitária professora-aluno e passou a ser um trabalho conjunto das professoras com os alunos das 1as. e 2as. séries. O TDI foi substituído pelo GAP, ou seja, Grupo de Apoio.

Este iniciou as suas atividades nos primeiros meses do ano letivo de 2005. A partir das dificuldades manifestadas pelas crianças que seriam atendidas nesses encontros, as professoras definiram quais os eixos com os quais cada uma delas iria trabalhar e, em função disso, desenvolveram um trabalho conjunto, no momento do planejamento, ao pensar nas atividades que iriam oferecer aos alunos que participariam desse espaço. Em cada encontro do GAP, os alunos podiam fazer rodízio ao realizar as atividades propostas pelas professoras. Os alunos tinham possibilidades de trabalhar diferentes aspectos com cada professora: leitura, interpretação de textos, produção de textos, etc. Assim, no mesmo espaço físico estavam juntas as quatro professoras, sendo cada uma delas responsável por um grupo determinado de alunos.

Gostaria de resgatar as falas da professora Andréa que, a partir da instauração do GAP, refletiu sobre a necessidade de estabelecer mudanças na estrutura organizativa da/s escola/s para, de fato, atender as necessidades de aprendizagem de todos os alunos.

CE5 - GA7 14 de abril de 205, registro de Andréa.

Em vários momentos das trocas desse encontro, reportamo-nos ao Grupo de Apoio em que descobrimos crianças que leem e escrevem, mas que em sala de aula, junto a seu grupo/série, não acompanham as atividades porque seu "tempo" é outro. [...]

A partir disso, de outras discussóes desse encontro, de outros encontros anteriores, e até de momentos do ano passado, começamos a sonhar..., a sonhar com uma escola organizada de uma outra maneira onde, por exemplo, as diferentes necessidades, os diferentes níveis pudessem ser trabalhados; onde a reclassificação pudesse ser uma prática não apenas num momento específico de início de ano, mas ao longo do processo (destaques meus).

7. CE — Código relativo ao Caderno da Escola que continha os registros semanais dos encontros do Grupo de Reflexão sobre Letramento e Alfabetização. 
A constituição do GAP foi uma estratégia que o grupo de professoras encontrou para, juntas, desenvolverem uma ação que promovesse a inclusão de todas as crianças das primeiras séries. Assim, enfrentavam os conflitos, fazendo-se responsáveis pela aprendizagem das crianças que, no espaço da sala de aula, não conseguiam aprender. Talvez essa ação conjunta tenha permitido que as professoras começassem a enxergar a força que a estrutura da escola tem sobre sua prática. Segundo Zeichner (2002), é importante que os professores percebam como é que a estrutura da escola "controla seu trabalho e afeta profundamente seu relacionamento com seus companheiros professores, seus alunos e as famílias dos estudantes. Os professores devem se sentir livres para expressar estes insights e para dar voz a suas preocupaçōes" (p. 40-41).

Acredito que as professoras que participavam do GA, ao tomar consciência de sua prática na sala de aula, conseguiram também ampliar o seu olhar, o que lhes permitiu enxergar como a estrutura escolar, de fato, condicionava a sua ação na escola.

\section{As dimensões do trabalho coletivo}

Para ampliar a concepção teórica acerca da coletividade, trago as consideraçōes da professora Andréa, que enfatiza as potencialidades desse trabalho conjunto realizado pelas professoras no GAP.

FT110 - Conversa com a professora Andréa, 8 de junho de 2005

Esse trabalho coletivo ajuda até para que você consiga realmente dar essa atenção maior, que é o que essas crianças precisam nesse momento... [...] Porque eu sinto assim: a gente, além de centrar essa força nessas crianças, vê que esse trabalho é conjunto mesmo, uma ajudando a outra, então, por exemplo, o ano passado era uma coisa muito isolada, eu ficava lá no meu mundo pensando em atividades, estratégias para recuperar aquelas minhas crianças e cada um fazia isso. Eai, esse ano, eu sinto assim, por exemplo, quando a gente estava a semana passada organizando esse apoio das crianças que começaram ontem a la. série, a gente está junto. Então a Cidinha veio com as ideias dela, eu vim com as minhas, a Itala veio com as dela, e uma trouxe material, e outra trouxe e a gente juntou tudo, não vamos começar por aqui, essa troca, sabe? Então eu sinto que é mais um trabalho coletivo quando deveria ser individual, até pela proposta da Secretaria, mas aqui na escola tornouse um trabalho coletivo. [...]

As palavras da professora enfatizam a importância do trabalho conjunto e da ajuda mútua, indicando que, em outros momentos, a prática do reforço (o 
TDI) era um trabalho isolado, no qual cada uma procurava estratégias para dar conta de suas próprias crianças. O GAP possibilitou não só um trabalho coletivo entre elas, mas também uma observação pelas quatro professoras de todas as crianças e não só das crianças de sua sala.

A interlocução, o diálogo e as ações promovidas no GA a partir de 2004 favoreceram a constituição do que Bakhtin (1999) chama de "coletividade", isto é, a partir dos "vínculos materiais objetivos", o indivíduo consegue ter consciência das necessidades, dos problemas e, nesse sentido, está sempre em busca de caminhos que permitam resolver as dificuldades enfrentadas. O GAP apareceu como uma proposta do GA, a partir da "conscientização", por parte das professoras, das ações necessárias para atingir as crianças que precisavam de outros tempos na escola, ainda sabendo que isso não romperia com o sistema seriado instituído.

Para tratar da ideia de "coletividade", remeto-me a Bakhtin (1999) que considera que uma "coletividade" está unida por vínculos materiais objetivos quando os membros dessa comunidade assumem a "atividade mental de nós", o que implica que esses indivíduos têm consciência de suas problemáticas e que, além disso, o lugar social que ocupam determina "que modelo, que metáfora, que forma de enunciação" será possível expressar a partir das experiências compartilhadas. Segundo Bakhtin (1999), a "atividade mental de nós", a consciência dos indivíduos de uma coletividade é mais diferenciada e assume um grau maior de consciência quanto mais forte e mais bem organizada e diferenciada for a coletividade na qual o indivíduo se orienta; assim, seu mundo interior, sua consciência será mais complexa.

Tentando fazer uma relação com a atividade desenvolvida a partir do GA, penso que, diante de uma problemática real, os membros desse grupo uniramse com o objetivo de procurar uma solução para as dificuldades achadas na escola e enunciar sua contrapalavra. Essa busca surgiu da conscientização de perceber que tinham poder de decidir, de saber que elas tinham em suas mãos a possibilidade de mudar alguma coisa e de saber de sua responsabilidade e de seu compromisso com os alunos. Assim, o GA, como "coletividade", buscou uma saída, uma brecha; a busca constituiu-se entre todas, e a solução foi achada pela coletividade, a resposta foi dada pela coletividade.

Todo esse processo vivido no GA permitiu-me pensar nas várias dimensões que possibilitaram a constituição de um trabalho coletivo. Penso que a conscientização ocorre no nível do pensamento, da atividade mental dos indivíduos nessa coletividade. As integrantes do GA pensaram, decidiram, refletiram sobre uma preocupação: como fazer para alfabetizar algumas crianças diferentes nos tempos e nos modos de aprender e como tratar do processo de avaliação dessas crianças. Do diálogo estabelecido no GA surgiu a possibilida- 
de de constituir o GAP. Assim, dentro do espaçotempo do GA, foram enunciados os caminhos que o grupo tomaria para objetivar a sua maior preocupação: que todos os alunos aprendessem. Nesse sentido, no pensamento, nas discussões, a "coletividade" aparecia, fazendo um trabalho coletivo. Levando em consideração o percurso do grupo para promover as ações em forma conjunta, pensei na existência de algumas dimensões do trabalho: a conscientização, que leva a uma decisão coletiva sobre uma ação a ser desenvolvida, e a dimensão real do trabalho coletivo, a dimensão de pôr na ação todas as ações analisadas e decididas coletivamente. A partir disso, gostaria de apontar quais os sentidos que me foram possíveis construir, a partir do GAP, para pensar nas dimensōes do trabalho coletivo nesse grupo: considero como dimensōes possíveis: "a contradição e/ou o conflito, a conscientização, a enunciação da resposta e a concretização na ação da enunciação" (Chaluh, 2008, p. 190).

Pensando nas dimensóes do trabalho coletivo aqui tratadas, destaco que a enunciação expressa por essa "coletividade" (as quatro professoras) implicou um trabalho coletivo; mas essa enunciação não implicou que cada uma das professoras tivesse abandonado suas marcas para efetivamente enunciar sua resposta. Ou seja, estou considerando que a enunciação da resposta foi a mesma, a solução achada foi a mesma. A "coletividade" decidiu enunciar que, diante da problemática com a alfabetização e os conflitos já tratados, o GA iria promover o GAP. E, se trago a questão das marcas, é porque foi uma questão que gerou uma importante reflexão dentro do grupo.

$\mathrm{O}$ trabalho coletivo desenvolvido pelas quatro professoras quanto à materialização do GAP deixou em evidência a questão de como lidar com as diferenças de posicionamento e pensamentos entre as professoras. Como respeitar as diferenças que poderiam surgir entre elas? Como fazer acordos quando, por exemplo, a avaliação das professoras em relação a determinados alunos não era a mesma? Ou quando tinham que definir que alunos poderiam ou não participar do GAP? Os acontecimentos vividos refletem que as decisões tomadas no grupo nem sempre foram consensuais, mas justamente é neste ponto que gostaria de destacar: para as professoras, a existência das diferenças entre elas foi considerada muito positiva, pois, segundo elas, essas diferenças - de perspectivas, estratégias, ações, concepções, etc.- foram percebidas como uma instância formativa para cada uma.

Foi Mabel, a diretora, que, em um dos encontros, mostrou as grandes diferenças existentes entre as quatro professoras e definiu essas diferenças como marcas. Tais marcas, segundo Mabel, eram questóes que poderiam ser percebidas pelo nosso jeito de trabalhar e mostravam nossas concepções de educação, escola, aluno, etc. As professoras destacaram que o interessante do estar juntas no GAP foi ver as marcas de cada uma delas porque, segundo elas, tinham a 
possibilidade de perceber como a outra colega trabalhava, quais eram suas intervençôes, como elas agiam diante de determinadas situações, oferecendo assim sugestôes/dicas/possibilidades para a sua prática. Elas apontavam que era justamente a diferença, a marca da colega, o que mais chamava a atenção em relação ao aspecto formativo desse encontro com elas. A experiência relatada por essas quatro professoras mostrou que o trabalho coletivo não implicou que cada uma das professoras saísse de sua prática, ou que saísse de suas marcas.

Como já afirmado, fazer um trabalho coletivo não implica apagar as diferenças entre os sujeitos envolvidos, muito pelo contrário. Quando as quatro professoras ficaram juntas no GAP, tiveram a possibilidade de conhecer as suas colegas de outra forma. Cada uma delas expôs-se no GAP como se comportava na sua sala de aula com os seus alunos, evidenciando, assim, suas próprias marcas às colegas. Esse mostrar-se para o outro permitiu que esse outro se formasse, aprendendo com seu colega. Segundo Riolfi (2002), a importância de um sujeito incluir-se em um grupo não basta para considerar esse espaço como um lugar para sentir-se protegido. A inclusão em um grupo tem, como aspecto fundamental, a possibilidade de entrar em um "movimento indissociável, me formar enquanto o outro se forma, cada um no seu tempo" (p. 41). O trabalho coletivo implica, por um lado, reafirmar as diferenças e, por outro, saber que, após esse trabalho, saímos diferentes do que éramos antes dele. No caso do GAP, penso que as professoras saíram diferentes ao assumirem a responsabilidade pela aprendizagem de todos os alunos.

Acredito que a questão das marcas mereça, ainda, mais uma consideração: pensar nelas como diferença e, nesse sentido, resgatar a sua importância na constituição de um grupo que tem a possibilidade de desenvolver um trabalho coletivo. Penso que Freire (2005) nos aponta a importância dessas diferenças:

Quando digo unidade na diversidade é porque, mesmo reconhecendo que as diferenças entre pessoas, grupos, etnias, possam dificultar um trabalho em unidade, ela é possível. Mas: é necessária, considerando-se a coincidência dos objetivos por que os diferentes lutam. A igualdade nos e dos objetivos pode viabilizar a unidade na diferença (p. 68, destaques meus).

\section{Algumas considerações}

A partir da experiência vivida com as professoras, resgato a importância da constituição de grupos de formação no espaço escolar. Quando um grupo tem como sustento a liberdade, oportuniza a cada um dos integrantes a possibilidade de colocar-se e expor-se, porque vinculados por um laço social (Riolfi, 
2002). A constituição de um grupo, segundo Riolfi (2002), parte do pressuposto de que uma pertença produtiva em um grupo faz-se justamente pela característica de que, para cada um dos sujeitos envolvidos, ele seja um lugar onde cada sujeito possa sentir-se sustentado por um certo laço que permite que, para além do estudo passivo de determinada área, ele se arrisque numa produção (p. 40). E, justamente, a constituição do GAP por parte das professoras foi uma das produções possíveis de serem construídas na escola. A possibilidade de tratar dos problemas comuns permitiu que estes fossem considerados como nossos, o que levou as professoras a buscar uma saída em forma conjunta. Tomar consciência dos problemas, dos conflitos e das dificuldades e assumir a corresponsabilidade na busca de possíveis soluções foram as instâncias que possibilitaram que as integrantes desse grupo se tivessem arriscado a uma produção. Talvez, quando um grupo de professoras na escola se arrisca a produzir coletivamente, as ações tenham como consequência a promoção do desenvolvimento da "autonomia profissional coletiva" (Davini, 2001).

Acredito, como aponta Zeichner (2002), que a formação reflexiva do professor, que fomenta seu verdadeiro desenvolvimento, só deva ser apoiada se estiver ligada à luta por uma maior justiça social e se, de alguma forma, contribuir para uma diminuição do abismo na qualidade da educação disponibilizada aos estudantes com diferentes backgrounds (p. 42). Nesse sentido, aponto que o trabalho desenvolvido pelo GA, quando na constituição do GAP, teve como pano de fundo a inclusão de todos os alunos, na tentativa de construir uma escola acolhedora para todas as crianças.

\section{Referências bibliográficas}

BAKHTIN, Mikhail. Marxismo e filosofia da linguagem. São Paulo: Hucitec, 1999.

CHALUH, Laura Noemi. Formação e alteridade: pesquisa na e com a escola. 2008. Tese (Doutorado em Educação): Faculdade de Educação, Universidade Estadual de Campinas, Campinas, 2008.

CORTESÃO, Luiza. O arco-íris na sala de aula? Processos de organização de turmas: reflexões críticas. Cadernos de Organização e Gestão Curricular. Instituto de Inovação Educacional, 1999. p. 1-23. Disponível em:

<http://www.dgidc.min-edu.pt/inovbasic/biblioteca/ccoge08/index.htm> Acesso em: 20 jun. 2007.

DALBEN, Ângela Imaculada Loureiro de Freitas. Conselhos de classe e avaliação: perspectivas na gestão democrática da escola. Campinas, SP: Papirus, 2004. (Coleção magistério formação e trabalho pedagógico).

DAVINI, Maria Cristina. La formación docente en cuestión: política y pedagogía. Buenos Aires: Paidós, 2001. 
FREIRE, Paulo. À sombra de mangueira. São Paulo: Olho D’Água, 2005.

FREITAS, Luiz Carlos de. Ciclos, seriação e avaliação: confrontos de lógicas. São Paulo: Moderna, 2003.

GAUTHIER, Clermont et al. Por uma teoria da pedagogia: pesquisas contemporâneas sobre o saber docente. Tradução de Francisco Pereira. Ijuí: Unijuí, 1998. p. 457. (Coleção fronteiras da educação).

GIMENO SACRISTÁN, José. Docencia y cultura escolar: reformas y modelo educativo. Buenos Aires: Lugar Editorial, 1997.

KRAMER, Sonia. Por entre as pedras: arma e sonho na escola. 3. ed. São Paulo: Ática, 2003.

PÉREZ de LARA, Nuria. Escuchar al otro dentro de sí: II parte. [Buenos Aires: FLACSO, 2006]. Disponível em: <http://virtual.flacso.org.ar/mod/book/print.php?id=3911> Acesso em: 13 jun. 2006.

RIOLFI, Claudia. O amor à diferença no trabalho enlaçado no interior de grupos. Trabalhos em lingüística aplicada, Campinas, v. 39, p. 37-45, jan./jun. 2002.

SMOLKA, Ana Luiza. A criança na fase inicial da escrita: alfabetização como processo discursivo. 11. ed. São Paulo: Cortez; Campinas, SP: Unicamp, 2003. (Coleção passando a limpo).

SPÓSITO, Marília Pontes. Educação, gestão democrática e participação popular. In: BASTOS, João Baptista (Org.). Gestão democrática. 2. ed. Rio de Janeiro: DP\&A, 2001. p. 45-56.

ZEICHNER, Kenneth M. Formando professores reflexivos para uma educação centrada no aprendiz: possibilidades e contradiçôes. In: ESTEBAN, Maria Teresa; ZACCUR, Edwiges (Org.). Professora-pesquisadora: uma práxis em construção. Rio de Janeiro: DP\&A, 2002. p. 25-54.

Recebido em 19 de maio de 2009 e aprovado em 18 de setembro de 2009. 